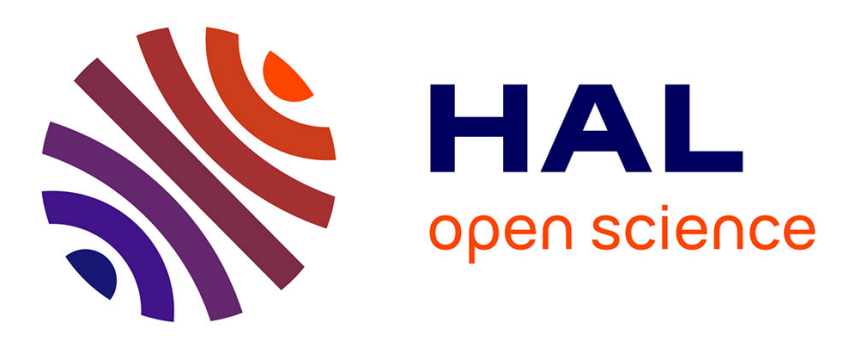

\title{
Synchronization of ultrafast pulses and pulse front tilt removal inside samples
}

Rémi Meyer, Chen Xie, Luc Froehly, Remo Giust, Luca Furfaro, Cyril Billet, François Courvoisier

\section{- To cite this version:}

Rémi Meyer, Chen Xie, Luc Froehly, Remo Giust, Luca Furfaro, et al.. Synchronization of ultrafast pulses and pulse front tilt removal inside samples. Conference on Lasers and Electro-Optics/Europe and the European Quantum Electronics Conference, Jun 2021, Munich, Germany. hal-03360038

\section{HAL Id: hal-03360038 \\ https://hal.science/hal-03360038}

Submitted on 30 Sep 2021

HAL is a multi-disciplinary open access archive for the deposit and dissemination of scientific research documents, whether they are published or not. The documents may come from teaching and research institutions in France or abroad, or from public or private research centers.
L'archive ouverte pluridisciplinaire HAL, est destinée au dépôt et à la diffusion de documents scientifiques de niveau recherche, publiés ou non, émanant des établissements d'enseignement et de recherche français ou étrangers, des laboratoires publics ou privés. 


\title{
Synchronization of ultrafast pulses and pulse front tilt removal inside samples
}

\author{
R. Meyer ${ }^{(1)}$, C. Xie ${ }^{(1,2)}$, L. Froehly ${ }^{(1)}$, R. Giust $^{(1)}$, L. Furfaro $^{(1)}$, C. Billet $^{(1)}$, F. Courvoisier $^{(1)}$ \\ (1) FEMTO-ST Institute, Univ. Bourgogne Franche-Comté, UMR CNRS 6174, \\ $15 B$ avenue des Montboucons, 25030 Besançon, France \\ (2) Ultrafast Laser Laboratory, Key Laboratory of Opto-electronic Information Technology of Ministry of Education, School of Precision \\ Instruments and Opto-electronics Engineering, Tianjin University, 300072 Tianjin, China
}

Ultrafast imaging requires accurate synchronization of pump and probe pulses, as well as the removal of any pulse front tilt of the probe pulse. Indeed, any pulse front tilt is highly detrimental to the accuracy of the imaging technique. In addition, the "zero delay" between pump and probe is only true for a specific propagation distance. This is because along the path of pump and probe beams, the dispersion strongly modifies the retardance between the pulses. As an example, for pump and probe beams in a collinear configuration, the propagation through $100 \mu \mathrm{m}$ thick glass slide is enough to induce a shift by more than $37 \mathrm{fs}$ between $800 \mathrm{~nm}$ and $400 \mathrm{~nm}$ pulses because of the difference in terms of refractive index. However, it is extremely difficult to characterize weak probe pulses.

Here, we solve both issues using an in-situ diagnostic, based on a transient grating generated by the pump pulse. Our technique is nondestructive and is performed within the sample to be characterized later by ultrafast imaging. The pump pulse is shaped as two interfering plane waves (red in Fig. 1), oriented in the Bragg condition for the probe beam (blue in Fig. 1). Thanks to the ultrafast electronic Kerr effect, the interference field is converted into a modulated index distribution, which diffracts the probe pulse with high efficiency. This is performed over a transient grating of only $10 \mu \mathrm{m}$ in conrtast with several $\mathrm{mm}$ conventionally needed for ultrafast Kerr shutters [1].

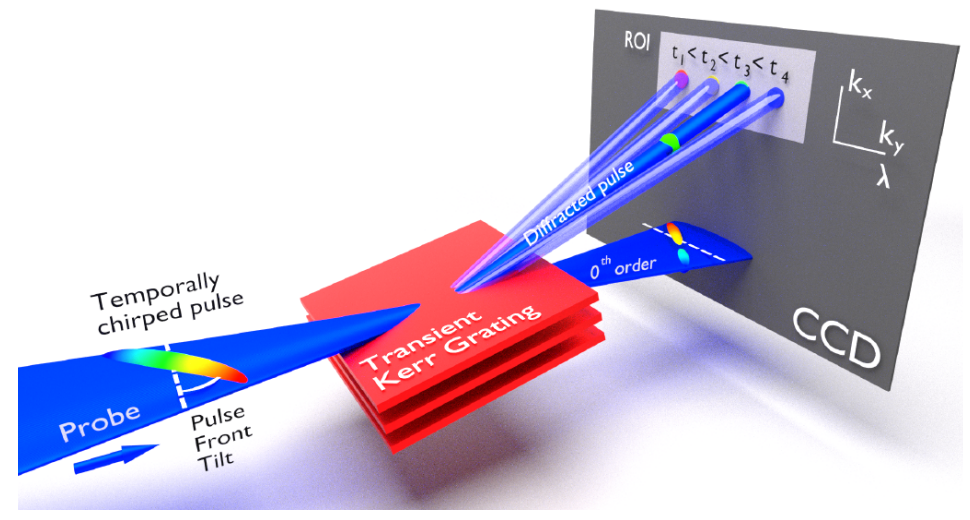

Figure 1: The transient grating created by the ultrafast pump pulse diffracts part of the spectrum of the streched probe pulse. In the far-field, the evolution of the diffracted beam direction with delay allows us for characterizing the angular dispersion and pulse front-tilt.

The diffracted signal obviously provides information of the relative delay between the probe pulse and the pump pulse, it can be very conveniently used to adjust the probe pulse compression, for instance to compensate the dispersion of thick microscope objectives used for imaging and focusing the beams. Most interestingly, we have analyzed the evolution of the far field signal as a function of pump probe delay and we report a technique to cancel the pulse front tilt which is dramatically high when high magnifications are used, as it is the case for high resolution ultrafast imaging.

Our technique is valid for any probe wavelength, is nondestructive, can be used in most in all pump-probe geometries. Most measurements only take about 1 minute so that they can be repeated as many times as necessary, for instance at each sample replacement or at each sample shift, to obtain later extremely reliable ultrafast imaging/spectroscopic measurements.

This research has received funding from H2020 European Research Council (ERC) under grant agreement 682032-PULSAR. This work was granted access to HPC resources PRACE( Project PULSARPIC PRA19_4980), TGCC (Project A0070511001), and Mésocentre de Calcul de Franche-Comté.

References

[1] J. Etchepare, G. Grillon, A. Migus, et al, Efficient femtosecond optical Kerr shutter, Appl. Phys. Lett. 43 , 406407 (1983).

[2] C. Xie, R. Meyer, L. Froehly, et al, "In-situ diagnostic of femtosecond laser probe pulses for high resolution ultrafast imaging", submitted (2021) 